\title{
PERSPECTIVAS PARA O DIREITO AGROAMBIENTAL A PARTIR DA NOÇÃO DE DESENVOLVIMENTO RURAL
}

\section{João Daniel Macedo Sá ${ }^{1}$}

\section{Resumo}

O presente trabalho se propõe a discutir as perspectivas do desenvolvimento rural no Brasil. Para tanto, procura identificar como historicamente se constrói a noção de desenvolvimento rural e se existe uma questão estrutural que interliga a pobreza e a concentração de terras no meio rural. Nesse sentido, apresenta uma crítica às políticas públicas com enfoque setorial, por não darem a devida atenção à obtenção, pelos indivíduos, do conjunto de capacidades e funcionamentos ligados às condições mínimas para uma vida digna. Conclui que a questão da terra está diretamente ligada à renda e riqueza, mas defende que a pobreza possui múltiplas dimensões, que impedem o exercício das capacidades básicas, colocando as pessoas em situações de extrema dificuldade e privação. Por isso, argumenta que as políticas públicas devem ser pensadas e planejadas de maneira integrada, de modo a buscar essa ampliação das capacidades humanas.

Palavras-chave: Desenvolvimento rural, Terras, Capacidades.

\section{PERSPECTIVES FOR AGRO-ENVIRONMENTAL LAW FROM THE NOTION OF RURAL DEVELOPMENT}

\begin{abstract}
The present work intends to discuss the rural development perspectives in Brazil. In order to do so, it seeks to identify how the notion of rural development is historically constructed and whether there is a structural issue linking poverty and land concentration in rural areas. In this sense, it presents a critique of public policies with a sectorial focus, because they do not give due attention to the achievement by individuals of the set of capabilities and functioning's linked to the minimum conditions for a decent life. It concludes that the land issue is linked directly to income and wealth, but argues that poverty has multiple dimensions, which prevent the exercise of basic skills, putting people in situations of extreme difficulty and deprivation.
\end{abstract}

\footnotetext{
${ }^{1}$ Doutor em Direito. Professor Adjunto da Universidade Federal do Pará. Advogado e consultor jurídico.
} 
For this reason, we argue that public policies should be drawn and planned in an integrated way, in order to seek the expansion of human capabilities.

Keywords: Rural Development, Land, Capabilities.

\section{INTRODUÇÃO}

É recorrente na literatura jurídica a noção de que a miséria e a exclusão social da população rural seriam consequência do alto grau de concentração do direito de propriedade, ou seja, da desigualdade na distribuição da terra, pois isso estaria diretamente relacionado à renda.

Essa influência pode ser inicialmente atribuída à teoria econômica marxista, já que quem não detém o capital (no caso da economia rural, as terras), tem como única alternativa vender sua força de trabalho (mais-valia). Logo, a concentração do capital, por esse raciocínio, produz exclusão social.

Alguns estudos mais recentes sustentam uma nova fase do desenvolvimento agrário ${ }^{2}$, marcada por mudanças radicais no padrão de acumulação de riqueza na agropecuária, que já não dependeria apenas da terra, mas principalmente de investimentos em tecnologia e infraestrutura nas propriedades, conhecimento, capital humano e capacidade de gestão (BUAINAIN et. al., 2013).

Esses estudos defendem que, no Brasil, especialmente antes da década de 1980, a principal fonte de formação e apropriação de riqueza no campo era a terra. Em tal contexto, o espaço rural e a agricultura teriam sido determinados por mecanismos de ocupação das fronteiras em processos de acumulação principalmente patrimoniais, baseados na terra e no uso de mão de obra de baixíssima remuneração, sem que a produtividade jamais tivesse sido o motor principal do processo.

No entanto, a partir do final da década de 1990, o desenvolvimento agrícola e agrário teria experimentado nova, inédita e irreversível dinâmica produtiva e econômica, naquilo que diz respeito às fontes de produção da riqueza social rural (BUAINAIN et. al., 2013).

\footnotetext{
${ }^{2}$ Ao longo deste trabalho serão apresentadas e discutidas algumas semelhanças e diferenças acerca dos conceitos de desenvolvimento rural, desenvolvimento agrário e desenvolvimento agrícola.
} 
A partir dessa ótica, antigos dilemas relacionados à produção de alimentos, ao fomento do desenvolvimento industrial, e à melhoria da distribuição de renda estariam sendo superados pelas transformações rurais, tendo como resultado a diminuição da importância do papel destinado à redistribuição de terras como um dos objetivos do desenvolvimento agrário.

Referida hipótese defende que a pobreza rural é bem menor nas regiões dinâmicas do agronegócio, e que a superação dos problemas sociais já não depende de redistribuição de terras, mas de investimentos em educação e infraestrutura, além da criação de oportunidades fora da agropecuária.

Essa abordagem tem dois problemas que precisam ser analisados: o enfoque na renda e no crescimento econômico como critérios de desenvolvimento exitoso, e a desvinculação dos problemas sociais rurais à estrutura fundiária.

Para discutir essas questões, tentaremos identificar como se constrói e o que compreende a noção de desenvolvimento rural no Brasil. Na esteira dessa compreensão, também tentaremos determinar qual é a importância da propriedade (do direito de propriedade) para o desenvolvimento rural.

\section{O DESENVOLVIMENTO RURAL E SUAS FASES NO SÉCULO XX}

A discussão em torno do desenvolvimento rural acompanha a trajetória do discurso político e acadêmico que marcaram o século $\mathrm{XX}$, e tem pressionado por um novo olhar a respeito dos problemas vivenciados no mundo rural (NAVARRO, 2001).

Esse processo de discussão é diretamente influenciado pelos organismos internacionais, tais como o PNUD, o Banco Mundial. o FMI e a FAO, dentre outros. Uma variedade de temas ligados ao desenvolvimento rural no último século pode ser apresentada.

Discutem-se desde a modernização da agricultura vivenciada nas últimas décadas e as mudanças decorrentes das relações de trabalho, passando pela expansão do comércio internacional, até os problemas de segurança alimentar acentuados pelo crescimento populacional e a gradativa diminuição da população rural.

Para entender os contornos dessa questão, este trabalho se apoiará principalmente em Garcia (2002), que divide a discussão do desenvolvimento rural na América Latina em torno de três grandes momentos políticos: 1) o desenvolvimento comunitário; 2) a reforma agrária; e 3) o desenvolvimento rural integrado. 
Esses aspectos serão abordados a seguir.

\subsection{O desenvolvimento comunitário}

O desenvolvimento comunitário pode ser conceituado como sendo o processo em que os esforços da comunidade se juntam aos do governo para melhorar as condições econômicas, sociais e culturais, integrando as pessoas à vida do país, de modo que todos possam contribuir para o progresso nacional (GARCIA, 2002, p. 18).

A proposta do desenvolvimento comunitário parte da ideia de que dentro dos grupos sociais existem grandes potencialidades que os qualificam, ainda que com ajuda pontual, a enfrentar os problemas básicos que limitam o seu desenvolvimento. Esse processo de discussão, que teve início na década de 1930, intensificou-se a partir da década de 1940, e materializou suas primeiras experiências de apoio concedido pelos organismos internacionais na década de 1950.

Essas experiências, inicialmente conduzidas por organismos públicos e privados norteamericanos, foram implementadas na África e na Ásia, como resposta à influência provocada pela Revolução Chinesa e pela guerra fria. Na América Latina, esses programas foram introduzidos somente no final da década de 1950, em zonas pobres e com presença de populações indígenas.

Os aspectos centrais consistiam na satisfação das necessidades básicas da população, incentivo à participação da comunidade nos governos locais, e apoio a organização cooperativa para consolidar os pequenos arranjos produtivos e gerar empregos. Segundo Favareto (2010, p. 302), esses elementos ainda são muito presentes no discurso atual ligado ao desenvolvimento rural.

O declínio desse modelo a partir dos anos de 1960 pode em grande parte ser explicado pelo fato de não ter gerado rápidas respostas no aumento da renda e da produção nos projetos implementados, tendo apenas incentivado a organização social como condicionante prévio a essas melhorias (GARCIA, 2002, p. 20).

Nesse momento histórico, prevalece, com exceção de poucos países (como no México, por exemplo), a visão liberal clássica da propriedade $^{3}$, e pouca discussão a respeito das

\footnotetext{
${ }^{3}$ A noção de propriedade-liberdade não expressa apenas o poder absoluto e exclusivo do titular sobre a coisa, expressa também os limites da ação do Estado. O direito de propriedade impõe limites sobre o que os outros podem
} 
obrigações do Estado na garantia de um acesso mais equitativo ao direito de propriedade sobre as terras rurais.

\subsection{A reforma agrária}

Como se sabe, a origem das discussões em torno da necessidade de mudanças da estrutura fundiária agrária dos países, assim como o tema da função social, no século XX, remontam à Revolução Mexicana de $1910^{4}$.

A discussão em torno da função social remete à noção de que o direito de propriedade passa gradativamente a ser visto também como fonte de deveres, ou na máxima propugnada pela Constituição Alemã, a noção de que a propriedade obriga. Esse processo não é uniforme, mas exerceu considerável influência nos países da América Latina ${ }^{5}$ ao longo do século XX.

Como enfatizam Garcia (2002) e Favareto (2006; 2010), o crescimento dos movimentos revolucionários e de contestação pela América Latina fez com que o tema da reforma agrária fosse gradativamente ganhando destaque e passasse a ser visto a partir da década de 1950 como a principal proposta política de desenvolvimento rural vinculada à necessidade de mudanças estruturais.

Processos semelhantes e que efetivamente culminaram com mudanças da estrutura fundiária ocorreram na Ásia, como por exemplo no Japão (de 1946 a 1950), na China (a partir de 1949) e na Coréia do Norte (final dos anos de 1940).

Veiga (1984, p. 38) acrescenta, dentre vários casos, também as modificações na distribuição da propriedade da terra ocorridas na Itália e em Formosa, com o objetivo de facilitar o desenvolvimento do capitalismo, e as modificações ocorridas no Leste Europeu e nos Balcãs, por conta da expansão do socialismo.

ou não podem fazer. Nesse caso, o direito de propriedade é intrinsecamente importante, mas não impõe nenhum dever de ajudar os outros a atingirem seus direitos. Sarmento (2004) explica que no início do século XX, a organização do direito privado estava pautada eminentemente na garantia da propriedade e da liberdade contratual. Os direitos fundamentais, nesse momento, constituíam principalmente limites ao poder do Estado.

${ }^{4}$ Deve ser ressaltado que além da reforma agrária mexicana, outra grande reforma agrária ocorrida no início do século XX é a da Rússia, num contexto em que "a aliança do campesinato com operários e soldados fez com que a revolução burguesa fosse rapidamente sucedida pela queda da própria burguesia e a consequente transformação socialista de um conjunto de nações que deram origem à União das Repúblicas Socialistas Soviéticas" (Veiga 1984, p. 37).

${ }^{5}$ Segundo Marés (2003, p.89). o termo função social "é unânime na doutrina agrária do continente, mas não nas leis nacionais. A peruana, por exemplo, chamou de uso em harmonia com o interesse social; a colombiana, adequada exploração e utilização social das águas e das terras; a venezuelana e a brasileira, que têm a mesma matriz, usaram o nome função social da propriedade". 
Todos esses movimentos acabaram por influenciar os organismos internacionais. Em novembro de 1950, a ONU encomendou à FAO a realização de estudos para verificar a relação entre os regimes de propriedade e os baixos níveis de desenvolvimento identificados na América Latina. Um estudo realizado em julho de 1951 indicou alta e desigual distribuição da propriedade, marcada por latifúndios, em contraste com a presença de minifúndios que tornavam insuficientes os recursos para garantir a subsistência e o emprego das famílias camponesas (Garcia, 2002. p. 17).

Quase que simultaneamente, os trabalhos da Comissão Econômica para a América Latina e o Caribe $^{6}$ (CEPAL) apontavam o lento crescimento da produção em relação às demandas nacionais e internacionais e indicavam a necessidade de modernização dos sistemas produtivos para aumentar os rendimentos, acompanhado de um processo de reforma agrária.

A lógica da reforma agrária, nesse momento está ligada a uma visão utilitarista ${ }^{7}$, pois o ponto de interesse da política fomentada era diminuir a pressão da influência dos movimentos revolucionários de cunho socialista. Ainda que o efeito de uma reforma agrária fosse positivo, a visão de mundo orientada para o desenvolvimento ainda estava vinculada à visão liberal clássica da propriedade.

Veiga (1984, p. 61) destaca que na América Latina, durante esse período, podem ser destacadas as reformas agrárias (ou tentativas de reformas) da Guatemala (1952), da Bolívia (1952). Some-se a isso a Revolução Cubana de 1959.

É nesse contexto que surge, em agosto de 1961, a Aliança para o Progresso, fruto da reunião de Punta Del Este, sugerindo mudanças das estruturas agrárias dos diferentes países da América Latina e a promoção da reforma agrária para alcançar uma distribuição mais justa da propriedade (GARCIA, 2002, p. 22).

Como resultado de Punta Del Este, criou-se também o Comitê Interamericano de Desenvolvimento Agrícola (CIDA). Um relatório produzido em 1966, fez o levantamento da questão agrária, apontando como causa de um sistema atrasado e de baixa produtividade a

\footnotetext{
${ }^{6}$ A CEPAL, criada em 25 de fevereiro de 1948, é uma das comissões econômicas regionais da ONU, e foi "criada para monitorar as políticas direcionadas à promoção do desenvolvimento econômico da região latino-americana, assessorar as ações encaminhadas para sua promoção e contribuir para reforçar as relações econômicas dos países da área, tanto entre si como com as demais nações do mundo. Posteriormente, seu trabalho ampliou-se para os países do Caribe e se incorporou o objetivo de promover o desenvolvimento social e sustentável").

${ }^{7} \mathrm{O}$ utilitarismo propõe a maximização da utilidade ou bem-estar, num sistema social e político de decisão, em que se submetem os interesses individuais aos interesses sociais. O problema é que o utilitarismo adota uma filosofia moral consequencialista, de forma que o julgamento das ações, regras ou instituições, e a própria ideia do sentido de certo ou errado, resulta da consequência que acarretam.
} 
concentração da propriedade da terra, que trazia consigo uma concentração de poder político. Esses aspectos foram considerados determinantes para condições de miséria prevalecentes no campo e a causa da alta migração para as cidades (GARCIA, 2002, p. 22; BAUER, 1998, p. 137).

Por isso, a década de 1960 é marcada por processos de reforma agrária de diferentes intensidades na América Latina, com exceção do Brasil, onde apesar dos esforços, não houve avanço em escala nacional, e de alguns países como Argentina e Uruguai, onde esse tema nunca foi considerado relevante.

As reformas possibilitaram a modificação de algumas relações sociais que sujeitavam os camponeses à exploração, e de um modo geral reduziram o poder dos grandes proprietários, favorecendo o aumento dos salários devido a maior organização do mercado de trabalho.

Apesar dos avanços, esperava-se impacto maior na produção agrícola, que só ocorreu num primeiro momento. Apesar do fortalecimento das organizações camponesas, a ausência de tecnologias apropriadas para os pequenos produtores, as dificuldades de acesso a crédito e um ambiente social e institucional desfavoráveis limitaram o consequente impacto das mudanças sobre a redução das desigualdades sociais.

Segundo Garcia (2002, p. 24), a chamada Revolução Verde não produziu nenhum impacto para os pequenos produtores rurais, organismos internacionais deram por fracassadas as políticas de reforma agrária, pois a pobreza rural persistia e aumentava.

Como resultado, houve um replanejamento da estratégia de desenvolvimento, e esses organismos passaram a enfatizar a necessidade de colocar à disposição dos países todos os elementos capazes de permitir uma melhoraria da qualidade de vida e das capacidades produtivas de regiões com alta concentração de pobreza.

\subsection{O desenvolvimento rural integrado}

Ao longo da primeira metade do século XX, verifica-se que tema da pobreza figurou de certo modo entre as principais dimensões do debate desenvolvido pelos organismos internacionais. Entretanto, é a partir da gestão de Robert McNamara no Banco Mundial (de 1968 a 1981), que o debate internacional incorpora definitivamente a ideia do combate à pobreza no discurso ligado ao desenvolvimento. 
Verifica-se aqui, uma aproximação com a outra concepção de propriedade, à medida que os organismos internacionais passam a reconhecer que um acesso mais equitativo ao direito de propriedade sobre as terras rurais poderia elevar a renda dos pobres, apesar de não terem sido direcionados esforços nesse sentido, diante do fracasso das políticas de reforma agrária tentadas anteriormente.

$\mathrm{O}$ enfoque orientado para o combate à pobreza esteve diretamente relacionado à definição do conceito de "pobreza rural absoluta", e foi fruto de pesquisas coordenadas por Hollis Chenery ${ }^{8}$, que, segundo Pereira (2010), resultaram na publicação do livro Redistribuição com crescimento, em 1974.

A tese fundamental defendia a ideia de que a redução da pobreza absoluta não era incompatível com o crescimento da economia, e a renda dos "pobres" poderia ser aumentada a partir da adoção de quatro estratégias distintas:

a) a maximização do crescimento do PIB através do aumento das poupanças e de uma melhor alocação dos recursos, o que beneficiaria, acreditavam os autores, todos os grupos da sociedade; b) a reorientação do investimento para os grupos-alvo em "pobreza absoluta" sob a forma de educação, acesso ao crédito, obras públicas etc.; c) a redistribuição de renda ou consumo para os grupos-alvo através do sistema fiscal ou da transferência direta de bens de consumo; d) a redistribuição de ativos existentes para os segmentos mais pobres, por meio de políticas como a reforma agrária (PEREIRA, 2010, p. 267).

Em 1974, em discurso proferido em Nairóbi, McNamara lança oficialmente a estratégia do Desenvolvimento Rural Integrado. A carteira de programas rurais financiados pelo Banco Mundial, que entre 1948 e 1960, giravam em torno de 6\% do financiamento total, passaram para 24\%. Mudanças semelhantes ocorreram no Banco Interamericano de Desenvolvimento (BID), e foi criado o Fundo Internacional de Desenvolvimento Agrícola (FIDA) (GARCIA, 2002, p. 25).

Ainda segundo Garcia, a carência de profissionais especializados para executar projetos de desenvolvimento com componentes sociais se mostrou um problema. A estrutura fundiária dos países, apesar de não ter sido colocada em discussão, continuou sendo obstáculo, pois em muitas regiões, isso afetava o próprio desenvolvimento dos projetos.

Favareto (2010, p. 303) destaca que nesse período vários países da América Latina estavam sob governos de exceção, sendo a "intocabilidade da propriedade fundiária um dos pilares desses regimes".

\footnotetext{
${ }^{8}$ Chenery era professor de Economia em Stanford e Harvard e trabalhou na USAID antes de assumir o cargo de economista-chefe do Banco Mundial.
} 
A proposta do desenvolvimento rural integrado gerou sérias contradições na fase aplicação, pois se por um lado os projetos eram demasiadamente detalhados, essa complexidade técnica exigida pelas metodologias de execução inviabilizava, na prática, a participação dos beneficiários (GARCIA, 2002, p. 27).

A tônica dos anos 1960 aos 1980 foi justamente a ausência de políticas estruturais para o mundo rural, ficando suas possibilidades de melhoria restritas à adequação às políticas macroeconômicas e de incremento tecnológico ou aos programas pontuais apoiados por organismos internacionais, na maior parte das vezes em resposta a situações de efervescência social. No caso brasileiro, isso pôde ser percebido com a instituição de uma forte modernização tecnológica, uma crescente integração da atividade agrícola aos complexos agroindustriais, e a formação de um padrão corporativista de organização do agro em que cabia ao Estado, a um só tempo, o papel de indutor da economia e de repressor dos conflitos que daí emergiam (FAVARETO (2010, p. 304).

O início da década de 80 é marcado pelo esvaziamento do discurso ligado ao combate à pobreza, questão que só retorna na agenda operacional do Banco Mundial a partir de 1986,

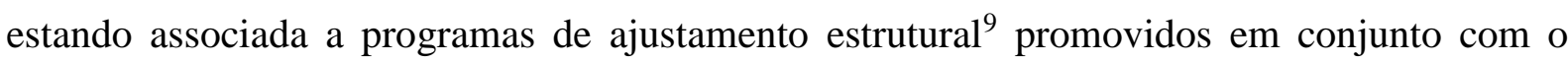
Fundo Monetário Internacional (PEREIRA, 2010, p. 268).

Veja-se que na fase do chamado desenvolvimento rural integrado, o aumento da renda e o crescimento econômico são os critérios utilizados para avaliar o sucesso do desenvolvimento dos países.

Embora a produção de alimentos tivesse acompanhado o crescimento da economia, houve um aumento da pobreza e da desigualdade. Desse modo, os organismos internacionais irão influenciar a agenda dos governos recolocando o tema do desenvolvimento em pauta, a partir da associação entre desenvolvimento rural, redução da pobreza e conservação dos recursos naturais (FAVARETO, 2010, p. 304).

\section{UM NOVO MARCO PARA O DESENVOLVIMENTO RURAL}

A partir de meados dos anos de 1990, ocorre uma reorientação dos conceitos de rural e de desenvolvimento rural. A FAO, por exemplo, passa a considerar o objetivo do desenvolvimento rural a partir de ações para melhoria das condições de vida e de trabalho das pessoas agrupadas em unidades familiares de produção e consumo (sejam agrícolas ou não) que viviam em zonas rurais (GARCIA, 2002, p. 51).

\footnotetext{
${ }^{9}$ Segundo Favareto (2010, p. 304), o ajuste estrutural, propiciou a execução de programas de modernização dos aparatos públicos, de ordenamento das economias, e a busca do crescimento sustentado, ocasionando o abandono de políticas específicas de desenvolvimento.
} 
Ainda nesse contexto, mas com alguns enfoques diferentes, outras organizações, tais como o IICA, o BID e o Banco Mundial, redefinem as concepções sobre o que representa o desenvolvimento rural.

Essa redefinição é compatível com a nova concepção de propriedade, à medida que reconhece que a pobreza possui múltiplas dimensões, e que as políticas públicas devem ser direcionadas para ampliar o conjunto de capacidades e funcionamentos dos indivíduos.

Como destaca Sen (1993), a avaliação da prosperidade econômica já não é o único objetivo do processo de planejamento das políticas públicas, pois diferentes componentes de bem-estar devem ser considerados para determinar o nível de desenvolvimento da população.

Assim, todos os organismos reconhecem:

a) o acirramento dos problemas ligados ao meio rural;

b) que o rural não está ligado apenas à agricultura;

c) que existe crescente relação entre urbano e rural; e

d) destacam a visão territorial do rural, que deve levar em consideração as múltiplas atividades existentes em cada contexto regional.

\subsection{O que compreende o desenvolvimento rural com enfoque territorial?}

Para Navarro (2001), não é possível considerar que os conceitos de desenvolvimento rural, desenvolvimento agrário e desenvolvimento agrícola sejam sinônimos, como também não é possível estabelecer uma definição única para cada termo, pois tais conceitos foram sendo alterados ao longo do tempo.

A noção de desenvolvimento agrícola conteria sentido estritamente produtivo, que diz respeito às condições da produção agrícola (e/ou agropecuária) e suas características em determinado período de tempo (NAVARRO, 2001, p. 86) ${ }^{10}$.

Já o desenvolvimento agrário abrangeria, além do estudo sobre as condições de produção, as análises históricas sobre as relações e mudanças sociais, econômicas, políticas e estruturais em determinado período de tempo.

Sob tal expressão, as condições próprias da produção (o desenvolvimento agrícola) constituem apenas uma faceta, mas a análise centra-se usualmente também nas instituições, nas políticas do

\footnotetext{
${ }^{10} \mathrm{O}$ desenvolvimento agrícola "refere-se, portanto, à base propriamente material da produção agropecuária, suas facetas e evolução - por exemplo, área plantada, produtividade, formatos tecnológicos, economicidade, uso do trabalho como fator de produção, entre outros tantos aspectos produtivos".
} 
período, nas disputas entre classes, nas condições de acesso e uso da terra, nas relações de trabalho e suas mudanças, nos conflitos sociais, nos mercados, para citar alguns aspectos.

Para este autor, o desenvolvimento rural, enquanto objetivo do Estado, vincularia as ações governamentais à definição de estratégias, metas, metodologias de implementação, e lógica operacional próprias com intuito de viabilizar as mudanças sociais pretendidas. $\mathrm{O}$ conceito se diferencia dos demais por pretender "uma ação previamente articulada que induz (ou pretende induzir) mudanças em um determinado ambiente rural”, com objetivo de proporcionar melhoria do bem-estar das populações rurais.

Isso explica por que, na sua visão, alguns desses conceitos seriam alterados ao longo do tempo. O conceito de desenvolvimento rural "altera-se também ao longo do tempo, influenciado por diversas conjunturas e, principalmente, pelos novos condicionantes que o desenvolvimento mais geral da economia e da vida social gradualmente impõem às famílias e às atividades rurais" (NAVARRO, 2001, p. 88).

Favareto (2010), por sua vez, defende que não faz mais sentido tratar o rural como sinônimo do agrário, e que o desenvolvimento rural deve ser compreendido principalmente por sua natureza eminentemente territorial.

O enfoque territorial parte do pressuposto de que a viabilidade do desenvolvimento rural depende da organização de instituições que sejam capazes de desenhar políticas públicas e programas sociais de forma integrada, e não pelo enfoque setorial.

No Brasil, o enfoque setorial se reflete no arranjo institucional governamental que orienta a condução das políticas públicas dispersas entre os inúmeros Ministérios ${ }^{11}$. Esse enfoque faz com que as políticas públicas sejam setorizadas, e não dialoguem entre si.

$\mathrm{Na}$ linha do enforque territorial, segundo Guedes e Reydon (2012), o arranjo institucional brasileiro, principalmente no âmbito do cadastro e do registro de imóveis por exemplo, impede a emergência de estruturas de direito de propriedade mais eficientes, tanto do ponto de vista econômico, como social.

Por isso, além da questão estrutural, alguns estudos também sugerem que o enfoque territorial do desenvolvimento rural é mais adequado ao enfrentamento dos problemas ligados à pobreza no campo.

Uma das vantagens de se utilizar a política de desenvolvimento territorial para enfrentar o problema da pobreza é que este tipo de política permite concentrar esforços e recursos financeiros em um determinado espaço geográfico, gerando-se efeitos cumulativos e irradiadores que possam potencializar a articulação e os próprios resultados dos distintos

\footnotetext{
${ }^{11}$ Veja-se, por exemplo, o Ministério da Agricultura, que direciona seus esforços para o agronegócio, em oposição ao Ministério do Desenvolvimento Agrário, que tem como eixo principal o apoio à agricultura familiar.
} 
programas implementados. Em grande medida, isso se deve à possibilidade de se articular (sic), ao mesmo tempo, diversas ações capazes de atacar as diferentes dimensões do fenômeno da pobreza (MATTEI, 2013, p. 118).

A questão da terra está diretamente ligada à renda e riqueza, mas a pobreza possui múltiplas dimensões, que impedem o exercício das capacidades básicas, colocando as pessoas em situações de extrema dificuldade e privação.

$\mathrm{O}$ enfoque territorial orientado para o desenvolvimento rural se afigura vantajoso à medida que considera que a distribuição equitativa do direito de propriedade em determinado espaço geográfico representa apenas uma das ações capazes de atacar o fenômeno da pobreza, já que considera que o direito de propriedade é intrinsecamente importante e instrumentalmente valioso, pois cria oportunidades sociais e econômicas para as pessoas.

\subsection{Desenvolvimento rural sustentável}

O início do debate institucionalizado sobre o desenvolvimento sustentável ocorreu com a publicação do relatório Os Limites do Crescimento (The limits to growth), pelo Clube de Roma em 1972. A partir da análise da pressão sobre os recursos naturais e energéticos, do aumento da poluição, o relatório fez previsões catastróficas quanto ao impacto da disponibilidade limitada de recursos naturais não renováveis, mesmo considerando o avanço tecnológico, caracterizando limites ao crescimento econômico, que se desconsiderados, poderiam afetar até mesmo a sobrevivência da espécie humana.

A consolidação do conceito de desenvolvimento sustentável no âmbito dessas organizações vem com a publicação do relatório Our common future (Nosso futuro comum) (WCED, 1987), ou Relatório Brundtland, como ficou conhecido.

Ao tratar dos problemas sociais, econômicos e ambientais, o Relatório Brundtland chamou atenção para os padrões de produção e consumo e sua relação com a pobreza no atendimento das necessidades mundiais, alertando para as limitações naturais em face do possível comprometimento da capacidade das gerações futuras de suprir suas próprias necessidades.

Os critérios adotados para medir o desenvolvimento, segundo Veiga (2005, p. 34) dividiram as pesquisas em estudos fundamentados na renda per capita, ou seja, na análise do crescimento econômico dos países; e estudos que partiam do processo histórico e cultural de cada país para explicar as enormes desigualdades existentes. 
Ao desconsiderar a diferença entre desenvolvimento e crescimento econômico, pressupunha-se que os países considerados "desenvolvidos" tinham se tornado ricos durante a revolução industrial, enquanto que permaneceram pobres os demais países, porque possuíam um incipiente parque industrial ${ }^{12}$.

Os críticos dos estudos de crescimento econômico desenvolveram análises qualitativas, baseadas no processo histórico e cultural de cada país, e atribuíram as disparidades entre países desenvolvidos e subdesenvolvidos ao processo de consolidação da sociedade e do Estado em torno do capitalismo que produziu diferentes padrões científicos e tecnológicos.

Segundo esses críticos, além dos problemas políticos e sociais enfrentados pelos países "subdesenvolvidos", as diferentes taxas de crescimento demográfico desempenharam papel determinante no processo de desenvolvimento, tornando mais complexa a relação entre renda e pobreza.

Para Sen (2000, p. 52), o desenvolvimento deve ser pensado como processo de expansão das liberdades reais das pessoas. Assim, o impacto do crescimento econômico dependerá mais do modo como o investimento público é aplicado (ou seja, como os frutos do crescimento econômico são aproveitados) do que da medição de riqueza de uma sociedade.

Por diversas razões históricas, como a ênfase na educação elementar e na assistência básica à saúde, além da conclusão de reformas agrárias eficazes no início do processo, a ampla participação econômica foi mais fácil de obter em muitas economias do Leste e Sudeste Asiático de um modo que não foi possível, digamos, no Brasil, Índia ou Paquistão, onde a criação de oportunidades sociais tem sido muito mais lenta, tornando-se assim uma barreira para o desenvolvimento econômico (SEN, 2000, p. 62).

No mesmo sentido, como assinala Matias (2015, p. 12), as três dimensões (ambiental, social e econômica) são indissociáveis, e refletem

a complexidade da sustentabilidade, que abrange não apenas a preservação do meio ambiente, mas também aspectos de justiça social, desenvolvimento econômico, valorização da cultura, da educação e da ética, entre outros que compõem o quadro necessário ao desenvolvimento das capacidades e ampliação das liberdades de cada indivíduo, melhorando a qualidade de vida e o bem-estar da humanidade como um todo.

A correlação entre o desenvolvimento rural e o desenvolvimento sustentável é evidente. Navarro (2001) critica os que pretendem ver adicionado o termo sustentável para proposição de um desenvolvimento rural sustentável, pois este serviria apenas para indicar a necessidade

\footnotetext{
${ }^{12}$ Confrontando essa hipótese, pode-se ilustrar o caso de alguns países, como o Brasil, que apresentaram intenso crescimento econômico no século XX, mas que não obtiveram significativa melhoria nos níveis de distribuição de renda e no acesso a serviços de saúde e educação (VEIGA, 2005, p. 97).
} 
da apropriada compreensão das dimensões ambientais que o próprio desenvolvimento rural, por definição, já contemplaria ${ }^{13}$.

Ocorre que a consolidação do princípio do desenvolvimento sustentável no âmbito internacional surge não somente por conta dos problemas ambientais, mas também como resultado da intensificação do processo de globalização, que ultrapassa as fronteiras dos estados nacionais.

Por isso, é necessário lembrar que a lógica da sustentabilidade inclui aspectos de justiça intergeracional. Não se trata apenas de discutir os problemas ambientais de maneira apropriada, e sim constatar que o progresso, conforme destacado no Relatório do Desenvolvimento Humano de 2014, é desafio que passa por "garantir que as escolhas e capacidades atuais não comprometam as escolhas e liberdades disponíveis para as gerações futuras" (PNUD, 2014, p. 45).

Independentemente da utilização do termo desenvolvimento rural ou desenvolvimento rural sustentável, o fato é que o desenvolvimento também deve ser pensado a partir da sua dimensão ambiental. Na linha do que vem sendo defendido por Veiga (2006, p. 90), as prioridades ambientais também podem ser encaradas em termos da sustentação das liberdades humanas.

No mesmo sentido, são as observações de Navarro (2001, p. 90):

será sempre necessário analisar-se corretamente o desenvolvimento agrícola para interpretar o desenvolvimento agrário de determinado país ou região, o que permitirá construir uma estratégia de desenvolvimento rural (ou, mais apropriadamente, por incluir dimensões ambientais, o desenvolvimento rural sustentável). Adicionalmente, sob tal estratégia, é provável que um conjunto de iniciativas no plano propriamente local (desenvolvimento local) será igualmente imprescindível (grifo nosso).

Uma visão jurídica do desenvolvimento sustentável, portanto, pode ser pensada a partir dos seguintes pressupostos:

1. analisado sob o aspecto do desenvolvimento deve-se defender o direito a um meio ambiente ecologicamente equilibrado, incluindo-o como elemento intrínseco da liberdade de escolha das pessoas (liberdade vista como oportunidade), sem o qual a degradação do meio ambiente gera uma restrição das capacidades humanas (uma forma de pobreza);

\footnotetext{
${ }^{13}$ Segundo Navarro (2001, p. 89), "embora certamente seja possível adicionar outros significados à noção de sustentabilidade (por exemplo, sustentabilidade política, social ou institucional, entre outras possibilidades), tais agregações já fazem parte do repertório analítico das tradições teóricas sobre o desenvolvimento rural".
} 
2. sob o aspecto da sustentabilidade, deve-se defender o compromisso ético com as futuras gerações, que se manifesta pela ideia de justiça intergeracional (SÁ, 2009, p.39).

O referencial adotado no presente ensaio, portanto, entende que os problemas do desenvolvimento estão condicionados não só pelo crescimento econômico, mas também por fundamentos de justiça social, que se manifestam a partir das oportunidades sociais, políticas e econômicas, vistas sob o aspecto da expansão das capacidades humanas (SEN, 2000).

Desse modo, é possível afirmar que os problemas do desenvolvimento analisados sob o enfoque das capacidades humanas em regiões rurais demandam a discussão sobre as oportunidades sociais, políticas e econômicas das pessoas, bem como a preocupação com os aspectos ambientais. Isso constitui, para a visão deste trabalho, o desenvolvimento rural sustentável.

\subsection{Desenvolvimento rural e suas implicações jurídicas}

Faria (2008, p. 14) trabalha com a noção de que o desenvolvimento se refere ao conjunto de transformações nas estruturas sociais e nas formas de comportamento que acompanham a acumulação no sistema de produção ${ }^{14}$. O papel do Estado no desenvolvimento é importante porque ele planeja (âmbito da formulação) e executa (âmbito da implementação) políticas, estabelecendo prioridades, metas e gerenciando recursos escassos para concretizar as referidas políticas.

Para este autor, numa perspectiva mais atual, não caberia mais discutir o direito sem levar em conta os desafios impostos pela justiça distributiva, frente às realidades sociais e econômicas do país. Desse modo, ao tema do crescimento econômico são incorporados novos componentes, tais como a sustentabilidade ambiental, o respeito à biodiversidade e a premissa de que países com distribuição mais equitativa de renda seguem padrões de crescimento de melhor qualidade do que aqueles que apresentam enormes desigualdades sociais.

Essas demandas impõem que seja realizada uma renovação do pensamento jurídico, a partir de nova compreensão, de forma a identificar como o direito pode ser utilizado enquanto

\footnotetext{
${ }^{14} \mathrm{O}$ texto citado refere-se à aula inaugural proferia em 12 de março de 2008, em razão da criação do Programa de Mestrado em Direito e Desenvolvimento, do curso de Direito da Fundação Getúlio Vargas (FGV) de São Paulo.
} 
vetor de redução de desigualdades, indutor do crescimento e de distribuição de renda em bases mais equitativas.

O contraponto interessante diz respeito a qual deve ser o papel do Estado, considerando a consolidação dos mercados globalizados, cuja ênfase se dá cada vez mais numa desregulação, liberalização e privatização.

Estamos vivendo também um período de transição no âmbito das ciências sociais, com o deslocamento de um paradigma de inspiração social-democrata, em cujo âmbito se destacam questões como desenvolvimento, distribuição de renda, Constituição-dirigente e justiça distributiva, rumo a um paradigma de inspiração tecnocrata, que enfatiza questões como interconexão financeira, estabilização monetária, desjuridificação, privatização, revogação de monopólios públicos, terceiro setor, pluralismo decisório e valorização do potencial autoregulatório da sociedade (FARIA, 2008, p. 35).

Uma das questões colocadas como desafio para essa nova compreensão do direito está, segundo Faria (2008, p. 41), justamente ligada ao estabelecimento de uma nova relação entre Estado e sociedade, e no "papel do direito como instrumento de implementação de políticas públicas e como reserva de valores éticos e morais a serem protegidos juridicamente”.

Como lembra Sen (1993), o princípio kantiano da necessidade de considerar os seres humanos como fins em si mesmos, e não como meios para outros fins (dignidade da pessoa humana), é importante para análises relativas à pobreza, progresso e planejamento.

Ou seja, o papel do direito reside justamente no processo de reflexão acerca dos valores morais que fundamentam o Estado de Direito brasileiro, conforme definido na $\mathrm{CF} / 88$, e que por isso mesmo devem ser juridicamente protegidos. Esses aspectos estão vinculados tanto ao processo legislativo, como à execução de políticas públicas (executivo), e a revisão dessas questões pela via judicial.

\section{CONSIDERAÇÕES FINAIS}

O enfoque setorial das políticas públicas impossibilita que o Brasil realmente comece a pensar o desenvolvimento rural de maneira adequada, pois as ações de planejamento, em regra, são pensadas por diferentes Ministérios, cuja direção é determinada por alianças políticas em que a divisão dos cargos ocorre de acordo com os interesses eleitorais.

Nessa mesma ótica, percebe-se que esses arranjos institucionais são ineficientes e favorecem uma distribuição muito desigual do direito de propriedade ao longo do tempo, perpetuando a manutenção da injustiça no campo. 
A ineficiência histórica do poder público, apesar de ser o maior detentor das terras da Amazônia por exemplo, não foi capaz de lidar com as demandas pelo seu acesso e utilização por particulares. Isso favoreceu a ocorrência de processos de apropriação indevida das terras e o acirramento das desigualdades econômicas e sociais.

É preciso avançar no debate em torno do espaço rural e na compreensão das estruturas básicas sob as quais se organizam a produção e a vida rurais. Faz-se necessário que o Estado realmente começar a planejar as políticas públicas de maneira integrada, associando o desenvolvimento rural com a redução da pobreza e a conservação dos recursos naturais.

\section{REFERÊNCIAS}

BAUER, Guilherme G. Télles. Sobre as origens da questão agrária brasileira. Ensaio. Revista de História Regional, Ponta Grossa, v. 3, n. 1, 1998. p. 135-166. Disponível em: <http://www.revistas2.uepg.br/index.php/rhr/article/viewFile/2056/1538>. Acesso em $15 / 01 / 2015$.

BUAINAIN, Antônio Márcio et. al. Sete teses sobre o mundo rural brasileiro. Revista de política agrícola, Brasília, DF: Secretaria de Política Agrícola do Ministério da Agricultura, Pecuária e Abastecimento, v. 22, n. 2, p.105-121, abr./maio/Jun. 2013.

FARIA, José Eduardo Campos de Oliveira. O papel do direito na construção do desenvolvimento. Cadernos Direito GV, v. 5, p. 13-41, 2008. Disponível em: <http://bibliotecadigital.fgv.br/dspace/bitstream/handle/10438/2822/caderno\%2520direito\%2 52026.pdf? sequence=1>. Acesso em: 10/02/2015.

FAVARETO, Arilson. Paradigmas do desenvolvimento rural em questão: do agrário ao territorial. Tese (Doutorado). Programa de Pós-Graduação em Ciência Ambiental, USP. São Paulo: USP, 2006.

A abordagem territorial do desenvolvimento rural: mudança institucional ou "inovação por adição"?. Estudos Avançados, São Paulo, v. 24, n. 68, 2010. Disponível em: $\quad<$ http://www.scielo.br/scielo.php?script=sci_arttext\&pid=S010340142010000100021\&lng=en\&nrm=iso>. Acesso em: 23/01/2015.

GARCIA, Alexandre Barril. Desarrollo rural: concepto, institucinalidad y politicas en el 2001. Santiago do Chile: IICA, 2002. Disponível em: <http://www.sidalc.net/repdoc/A9450E/A9450E.PDF>Acesso em: 24/01/2015.

GUEDES, Sebastião Neto Ribeiro; REYDON, Bastiaan Philip. Direitos de propriedade da terra rural no Brasil: uma proposta institucionalista para ampliar a governança fundiária. Rev. Econ. Sociol. Rural, Brasília, v. 50, n. 3, set. 2012 . Disponível em: $<$ http://www.scielo.br/scielo.php?script=sci_arttext\&pid=S010320032012000300008\&lng=en\&nrm=iso>. Acesso em: 31/01/2014. 
MARÉS, Carlos Frederico. A função social da terra. Porto Alegre: Sergio Antônio Fabris, 2003.

MATIAS, Eduardo Felipe P. O Direito Internacional da Sustentabilidade. Revista Jurídica Consulex, v. XIX, n. 432, p. 12-15, 2015. Disponível em: 〈http://www.consulex.com.br/〉. Acesso em 25 jul. 2016.

MATTEI, Lauro. Pobreza e política de desenvolvimento territorial: noções, metodologias de mensuração e estratégias de enfrentamento do problema. In: MIRANDA, Carlos; TIBURCIO, Breno (Orgs.). Políticas de desenvolvimento territorial e enfrentamento da pobreza rural no Brasil. Brasília: IICA, 2013. p. 89-123. Série Desenvolvimento Rural Sustentável; v.19.

NAVARRO, Zander. Desenvolvimento rural no Brasil: os limites do passado e os caminhos do futuro. Estudos Avançados, São Paulo, v. 15, n. 43, dez. 2001. Disponível em: $<$ http://www.scielo.br/scielo.php?script=sci_arttext\&pid=S0103-

40142001000300009\&lng=en\&nrm=iso>. Acesso em: 23/01/2015.

PEREIRA, João Márcio Mendes. O Banco Mundial e a construção político-intelectual do "combate à pobreza". Topoi, v. 11, no 21, jul.-dez. 2010, p. 260-282. Disponível em: <http://www.revistatopoi.org/numeros_anteriores/topoi21/Topoi21_14Artigo14.pdf>. Acesso em: 01/02/2013.

SÁ, João Daniel Macedo. Pagamento por serviços ambientais: perspectivas para a proteção e uso dos recursos naturais. Belém, 2009. Dissertação (Mestrado). Programa de Pós graduação em Direito, Universidade Federal do Pará. Belém, 2009.

SARMENTO, Daniel. Direitos fundamentais e relações privadas. Rio de Janeiro: Lumen juris, 2004.

SEN, Amartya. Desenvolvimento como liberdade. Tradução Laura Teixeira Motta, Ricardo Doninelli Mendes. São Paulo: Companhia das Letras, 2000.

O desenvolvimento como expansão de capacidades. Lua Nova, São Paulo, n. 28-29, abr. 1993. Disponivel em: <http://www.scielo.br/scielo.php?script=sci_arttext\&pid=S010264451993000100016\&lng=en\&nrm=iso>. Acesso em: 22/12/2014.

PNUD (Programa das Nações Unidas para o Desenvolvimento). Relatório do Desenvolvimento Humano 2013. Ascenção do Sul: Progresso Humano num Mundo Diversificado. Lisboa, Camões - Instituto da Cooperação e da Língua, 2014. Disponível em: $<$ http://vi.unctad.org/resources-mainmenu-64/digital-library?task=dl_doc\&doc_name=8562013-human-d\&lang=pt>. Acesso em: 14/02/2015.

VEIGA, José Eli da. Meio ambiente \& desenvolvimento. São Paulo: Editora Senac São Paulo, 2006.

Desenvolvimento Sustentável: o desafio do Século XXI. Rio de Janeiro: Garamond, 2005.

O que é reforma agrária. São Paulo: Abril cultural, Brasiliense, 1984. Coleção Primeiros Passos. 
WCED - The World Commission on Environment and Development. Our Common Future. Oxford, Inglaterra: Oxford Press, 1987. 